\title{
The Impact of Vegetation on Thermal Performance
}

\author{
Alamah Misni \\ Faculty of Architecture, Planning and Surveying, \\ Universiti Teknologi MARA, Shah Alam, Malaysia \\ alamahmisni@gmail.com
}

\begin{abstract}
This paper investigates the effect of vegetation in modifying outdoor temperature around a single-family house in a hot and humid tropical climate. The climatic parameters, house location, and physical characteristics of landscape design are measured and surveyed. The focus of this study is on the impact of trees and different types of foliage on the thermal environment of the houses. The main findings are that heavily landscape around single-family houses can potentially slow heat build-up by shading, evapotranspiration, and wind channelling by as much as $4^{\circ} \mathrm{C}$.
\end{abstract}

Keywords: Single-family house, thermal performance, landscape design, evapotranspiration

eISSN 2398-4295 @ 2018. The Authors. Published for AMER ABRA cE-Bs by e-International Publishing House, Ltd., UK. This is an open-access article under the CC BY-NC-ND license (http://creativecommons.org/licenses/bync-nd/4.0/). Peer-review under responsibility of AMER (Association of Malaysian Environment-Behaviour Researchers), ABRA (Association of Behavioural Researchers on Asians) and $c E-B s$ (Centre for EnvironmentBehaviour Studies), Faculty of Architecture, Planning \& Surveying, Universiti Teknologi MARA, Malaysia.

http://dx.doi.org/10.21834/ajbes.v3i11.110 


\subsection{Introduction}

In tropical climates, vegetation has significant effects to influence the microclimate. Vegetation cover can influence urban microclimates directly by shading surfaces and channeling the wind, and indirectly by evapotranspiration of water (Hashem Akbari, Davis, Dorsano, Huang, \& Winnet, 1992; DOE, 1993). The vegetative areas are capable of providing positive impacts on regulating high temperature in an urban area (Buyadi, Mohamad, \& Misni, 2013). Trees, grass, and shrubs will reduce air temperatures near the house and provide evaporative cooling. The type and species of trees used is very important. They should be selected according to the amount of shade they provide as well as their aesthetic appearance.

\subsection{Literature Review}

Shrubs and other low growing foliage provide shading during the morning and late afternoon when the sun is low in the sky. Shrubs planted close to the house will shade walls and windows. Vines provide a very fast growing source of shade for a building, and they require little space for growth. Shading is the most cost-effective way to reduce solar heat gain. Akbari et al.'s (1986) study in Los Angeles stated that planting trees can save as much as $34 \%$ of residential cooling demand on a hot summer day.

In hot and humid tropical climates, the wind is an asset which can provide natural ventilation and convective cooling of hot exterior building surfaces. Olgyay (1963) suggests that the wind is particularly important for comfort when temperatures are above $29^{\circ} \mathrm{C}$ and relative humidity (RH) above 50\%. In these cases, cooling needs are high and landscaping around the buildings should be directed to channelling cooling breezes, and to minimize humidity closest to the house. McPherson, Herrington, and Heisler (1988) suggest that in hot and humid climates, high-branching and wide canopy trees and low ground covers should be used to promote shade and encourage the wind.

The evapotranspiration process can reduce surrounding air temperatures. Heisler has stated that trees are effective for cooling because they absorb $70-85 \%$ of the heat from solar radiation by transpiration (cited in Akbari et al., 1992). Since leaves are generally dark and coarse and thus reflect very little light, they make ideal solar radiation absorbers and controllers. The leaves have the highest light absorption: about $50 \%$ of the total solar energy (Taiz \& Zeiger, 2006). DOE (1995) reported that planting three trees per house could reduce heat build-up and the city heat island effect by shading, and evapotranspiration. It would reduce surrounding air temperatures by up to $5^{\circ} \mathrm{C}$ (DOE, 1995; Foster, 1994). Similarly, groundcover such as grasses or turf also has a cooling effect from evapotranspiration. The temperature above a groundcover can be $10-15^{\circ} \mathrm{F}$ cooler than above a heat absorbent material (Morgan et al., 2000). Careful landscape planning can potentially reduce the amount of sunlight heating building surfaces and can prevent reflected solar radiation from entering the home. 


\subsection{Methodology}

Research methods in this study were divided into three parts: houses with a surrounding landscape selection, observation, and field measurement for weather data and landscape elements.

\section{House selection}

The particular site studied is in Precinct 14 Putrajaya, Federal Territory Putrajaya, Malaysia. The elevation is of the order of $80 \mathrm{~m}$. Putrajaya is the administrative capital was developed as a 'garden city'. The approach of tropical architecture for a single-family residence in this area is to conserve as best as possible the natural environment (PJH, 2001). The area of development consists of 27 houses was located in well-planned community area which represents around $5 \%$ from the residential zone. This low-density development site was surrounded by a wide green open space sited on very gentle slopes. The two houses were chosen and labelled as a heavily landscaped house (house A) and sparsely landscaped house (house B), because of similar criteria; under 5 years' development, medium size of the house, used a standard of construction, but different in their landscape treatments and orientation.

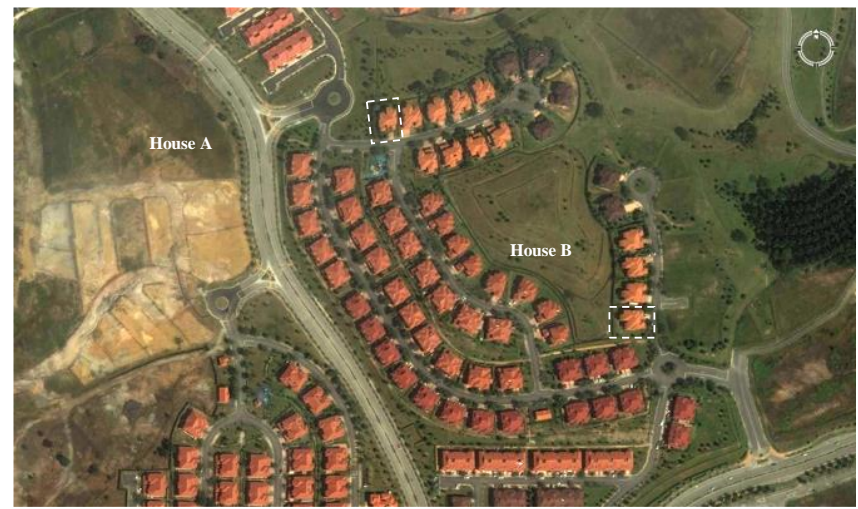

Figure 1. Location of two single-family residences in Precinct 14 , Putrajaya $\left(2^{\circ} \mathrm{N}\right.$ Latitude, $101^{\circ} \mathrm{E}$ longitude).

Source: Google Earth (2010)

\section{Local weather recording}

Putrajaya is located in the equatorial doldrums area has a hot and humid tropical climate. The fieldworks measurement was carried out during daytime on 16-17th January 2010 with permission to do survey only during day time. Weather in these two days is very similar in sunshine for the whole day and start raining lightly at 19.30 hours. The study measured a climatic parameter and physical characteristic of four azimuths of the houses. Each measurement point represents an area of $90 \mathrm{~m}^{2}$ and approximately $3-10 \mathrm{~m}$ radius (exterior) 
around the fixed/mobile weather station. The measurements were to be taken at 30-minute intervals in all locations in $1 \mathrm{~m}$ above ground and in under shade situation. The field measurement of temperature, humidity and wind velocity in exterior and interior is divided into two areas of research:

\section{Exterior space}

The basic measuring equipment used include two sets of mobile TSI VelociCalc data loggers and sensor, and two sets of data acquisition devices, Babuc A, and sensors for the measurement of surface/ambient air temperatures, global temperature, $\mathrm{RH}$ and wind velocity.

\section{Interior space}

Four sets of Thermo Hygrometers have been used to measure air temperature, and air humidity data inside the buildings.
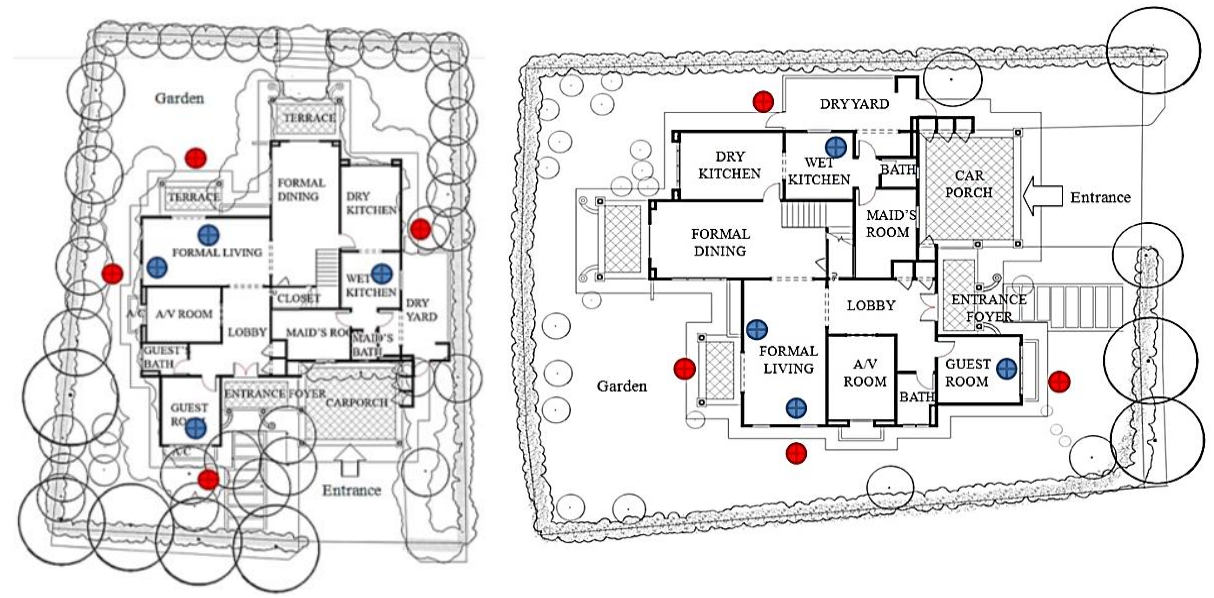

Figure 2. Outdoor and indoor measurement points at the house $A$ (left) and house $B$ (right)

\section{Landscape element measurement}

The study of all landscape elements was by researcher's observation and interviewed to the owner of the house. Landscape elements and house configurations were drawn to scale and detail. The location of every type of vegetation was stated and recorded in four azimuths (wall). According to Simpson (2002), a wall is cardinally oriented if the normal to the wall is within $\pm 45^{\circ} \mathrm{E}$ of a cardinal direction (N, E, S or W), otherwise, it is inter-cardinal (NE, SE, SW or NW). 


\subsection{Results and Discussions}

\section{Trees}

The house A had a lush, green garden, which had 47 types of trees, while the house B had only 11 trees. Trees are the most important plants in the study area for providing shade to the building and garden areas. The house A has a diverse range of trees. All were planted $3-9 \mathrm{~m}$ from the building in groups, so their canopies touched and overlapped. They covered approximately $60 \%$ of the garden area. Most of the trees at the heavily landscaped house (89\%) were still young (three years), with their canopy sizes below $3 \mathrm{~m}$ (small), $9 \%$ were small to moderately sized $(3-7 \mathrm{~m})$, and $2 \%$ were medium-sized. The majority of the trees ( 18 trees), were planted on the west side while the south and north sides had 12 trees each. Only 5 trees were planted on the east side. The average trunk height of trees in this garden was about $1.5 \mathrm{~m}$ and their overall height was $2-4 \mathrm{~m}$. However, a few trees such as Dalbergia oliveri had an overall height of around $9 \mathrm{~m}$, and small groups of Schizolobium parahyba can reach more than $15 \mathrm{~m}$ high. The majority of trees in this garden has a medium amount of leaves $(40 \%)$ while $30 \%$ of the trees had few or a dense amount of leaves respectively. Trees with small sized leaves were dominant in this garden (64\%) and the balance was medium sized leaves.

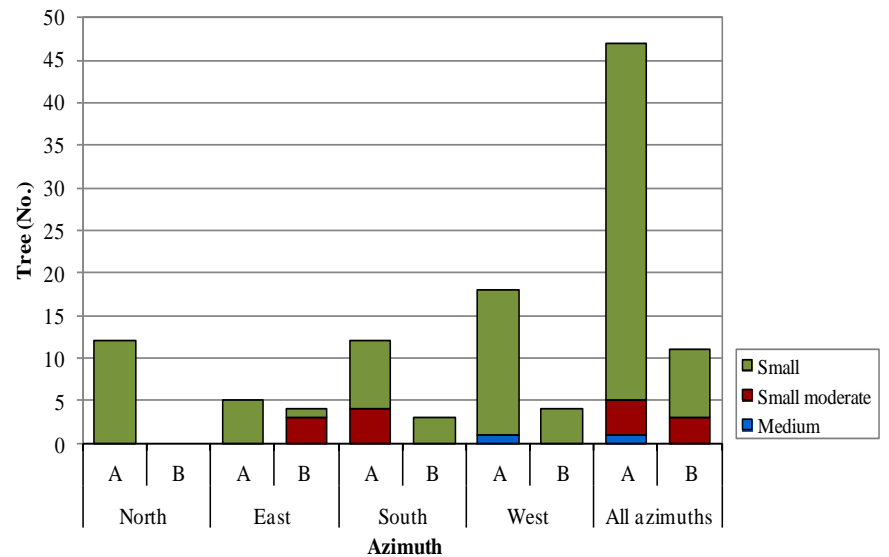

Figure 3. Trees distribution compared by tree sizes and tree azimuth in relation to the building to the house $A$ and house $B$

The house B had a small number of plant species. The trees were located $5-9 \mathrm{~m}$ from the house, and $73 \%$ of the tree canopy was small in size and $27 \%$ smaller to moderately-sized. The tree canopy only covered around $5 \%$ of the garden's surfaces and was focused mostly on the east side of the house. Samanea saman and Erythrina fusca were planted along the roadside. The majority of the trees (64\%) had an overall height of around $2-4 \mathrm{~m}$, and the remaining $36 \%$ were between $5-9 \mathrm{~m}$ overall height, with trunk heights around $2-2.5 \mathrm{~m}$. On average the trees had a sparse amount of leaves that were small. The canopy size of the 
trees in this garden was smaller.

\section{Shrubs, vines and groundcover}

The house A had 104 individual and group of shrubs, 10 plantings of vines, and 10 groups of groundcover. A group of Hymenocallis littoralis, Acalypha wilkensiana 'cultivar', Baphia nitida, and Eugenia oleina were placed as boundaries of the house. By comparison, the shrub population in the house B was very low. Only 34 individual and groups of shrubs were planted around the house. The lawns of both houses were covered by Axonopus compressus.

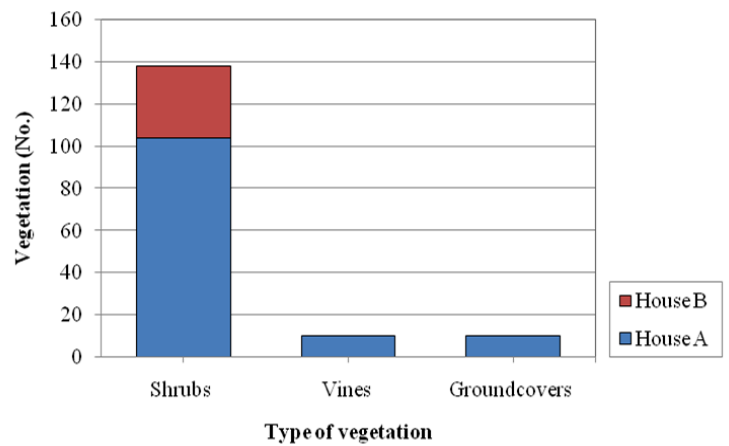

Figure 4. Shrubs, vines and groundcover distributions at the house A and B

\section{Weather data}

The solar radiation was recorded as early as 7.00 hours, with the reading as low as $0.05 \mathrm{MJ} . \mathrm{m}^{-}$ 2. Solar radiation gradually rose reaching the highest level of $2.37 \mathrm{MJm}^{-2}$ at 13.00 hours. Solar radiation uniformly decreased to the lowest reading of $0.01 \mathrm{MJ} . \mathrm{m}^{-2}$ at 20.00 hours. Overall, solar radiation in the study area was actively received between $10.00-18.00$ hours; a total of approximately eight hours per day. The amount of cloud on the day observed in the study area was 7 Okta.

The outdoor temperature around the house $B$ fluctuated until reaching the highest point of $36.9^{\circ} \mathrm{C}$ at 14.00 hours. The same pattern occurred at the house $\mathrm{A}$, which reached its highest temperature of approximately $33.8^{\circ} \mathrm{C}$ at 14.30 hours. Temperatures around both houses gradually fell during the afternoon in 16.30 hours. Both houses reached their lowest temperatures at 19.30 hours; 28 and $27^{\circ} \mathrm{C}$ at the house $\mathrm{B}$ and the house A respectively. Overall the exterior temperature of the house $A$ was as much as $4.0^{\circ} \mathrm{C}$ lower than the house $B$ during the peak time of the day.

The interior temperature at house $\mathrm{A}$ had gradually declined throughout the day to as low as $23.2^{\circ} \mathrm{C}$ at 16.30 hours, with as much as $3.2^{\circ} \mathrm{C}$ difference when compared to the house $\mathrm{B}$. After 17.00 hours the temperature gradually rose. The clear difference in temperature readings for the interiors of the two houses was influenced by exterior ambient temperatures. 

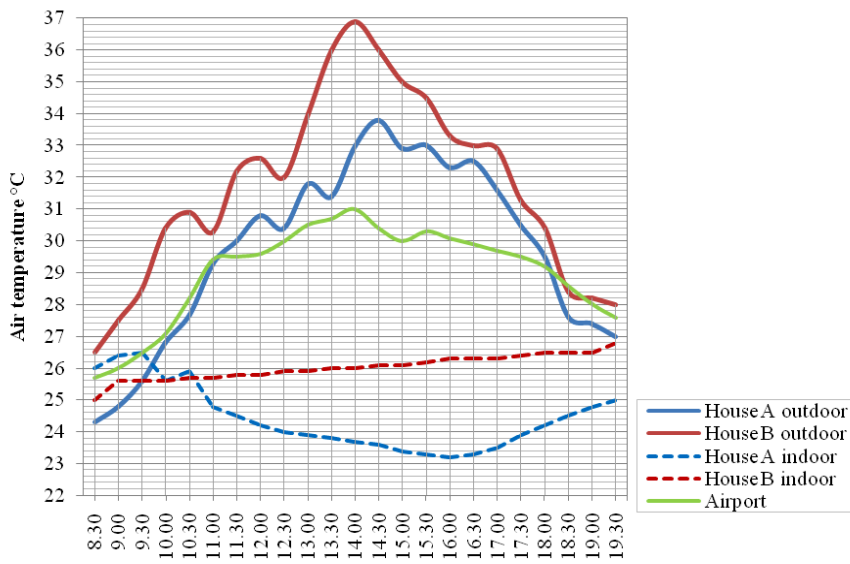

Time of the day (LST)

Figure 5. Outdoor and indoor temperature adjacent to the west walls of the house A and $B$

Both houses received slightly higher wind speeds in the morning, and fluctuating between $0.2-1 \mathrm{~m} / \mathrm{s}$ from 10.00 to 14.00 hours. The wind speed rose dramatically until reaching the highest point at $2.74 \mathrm{~m} / \mathrm{s}$ at 15.00 hours. It fluctuated between $0.9-1.3 \mathrm{~m} / \mathrm{s}$ between 16.30 19.30 hours. The wind blew in a fluctuating pattern throughout the day.

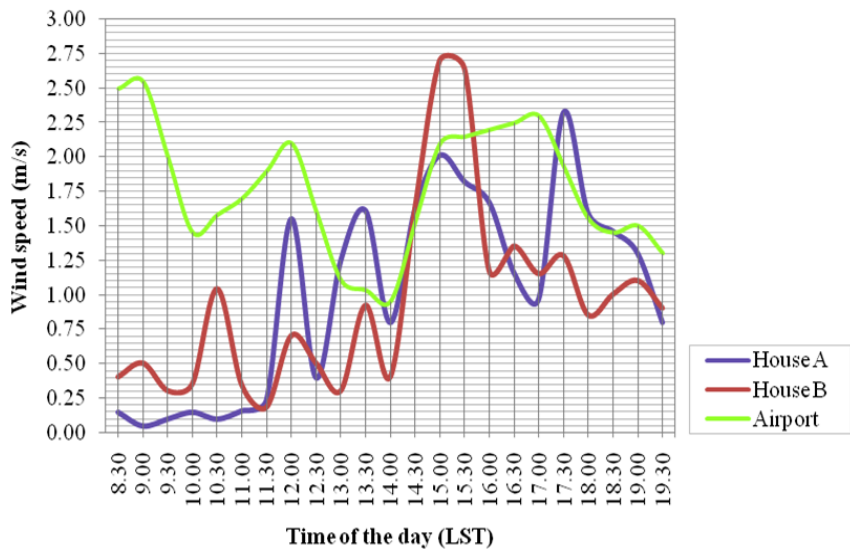

Figure 6 . Wind speed adjacent to the west walls of the house A and $B$

During the morning, the $\mathrm{RH}$ readings at the house $\mathrm{A}$ is higher around $10-23 \%$ difference. During the middle of the day, the $\mathrm{RH}$ levels of the house $\mathrm{B}$, were around $4-7 \%$ different higher to the house A. However, all houses had a similar reading at 19.30 hours with less 
than $15 \%$ difference in relative humidity.

\subsection{Discussion}

House A has practiced well design of landscaping while the house $B$ has a very minimum of landscaping. The good design of landscaping in this study contact means using the right amount of plants and every plant has proper placement and appropriate arrangement, size and shape, and precise plant species. The majority of shade trees around the two houses are in small sizes in height between 2 and $4 \mathrm{~m}$. Therefore, in the house $A$, the 47 of shade trees were planted in groups and multilayer which were located close to each others. Moreover, all shade trees were located in a strategic location which in distance 3-9m from the house, spread in all four azimuths. The average amount of leaves for these shade trees is medium to provide shade effectively. In the overall strategic arrangement of shade trees on the north and the west, wall area made the surface temperature as low as 33.5 and $33.8^{\circ} \mathrm{C}$ respectively. Conversely in the house $B$, the only 11 of shade trees were planted in individual and the amounts are too small which were only located in east and south sides. Less shade is provided by plants in an around the house $B$ has made the surface temperature at the west wall as much as $4.0^{\circ} \mathrm{C}$ higher than house $A$ during peak load.

In hot and humid tropical climate, shrubs and vines planted immediately adjacent to the exterior walls or windows can be effective acted as insulating properties from hot weather in all day long. House A planted vines in the north, east and south walls. Shrubs were planted in along their walls as in groups together with groundcovers. The average height of shrubs is in between 1 and $1.5 \mathrm{~m}$ is sufficient to cover walls by their shades. Vine planted in the north and south walls also in lush conditions climbing up to the first floor of the house. The house A exhibits lower value in interior walls than house $B$ since mid-morning until the afternoon. In north and west walls of the house $A$, the interior temperature reaches as low as $23.2^{\circ} \mathrm{C}$ at 16.30 hours compared to $26.2^{\circ} \mathrm{C}$ in the house $\mathrm{B}$. It delays the heating of the exterior ambient air during the day and helps keep lower interior temperatures. The air beneath the leaves cools down when the wall radiates back to the environment the heat gain during the day. Furthermore, the air of the interior house $A$ wall is lower than clear walls in the house $B$ house by $2-3^{\circ} \mathrm{C}$.

The wind speed in all azimuths of both houses is higher during the afternoon and evening because the strategic location of the house facing the wind direction and landscaping around had allowed the wind to pass through. The houses located at end lot is also an effective way to allow wind flow pass through to the house areas because no buildings obstructing the flow of the wind.

The increase in the $\mathrm{RH}$ levels in the outdoor environment was due to the existing of the landscaping around. The changes level of $\mathrm{RH}$ around House $\mathrm{A}$ is very stable and consistent because it was controlled by surrounding vegetation during evaporation and transpiration process and directly influenced by solar radiation. Its has been occurring influenced by amount, placement and size of the plant. The more vegetation on the earth surfaces the more evapotranspiration process will be occurring and can provide cooler atmosphere, which was 
$4^{\circ} \mathrm{C}$ lowered in the house $\mathrm{A}$ compared to surface temperatures of the house $\mathrm{B}$ during midnoon (14.00 hours).

\subsection{Conclusion}

This study focuses on vegetation in the urban environment at a physical scale of the medium size of a single-family house and its private garden. Analysis of the temperatures, $\mathrm{RH}$ and wind speeds of the heavily and sparsely landscape house of the outdoor and indoor facades revealed the passive cooling potential of landscaping. Strategic arrangement and design, sufficient numbers, and sizes of vegetation can provide the most efficient means of reducing exterior air temperature around a residential building. The combination of shade trees, shrubs, vines, and groundcovers was predicted found to be the most effective landscape strategy in term of the cooling provided, with the maximum air temperature reduced by up to $4^{\circ} \mathrm{C}$. This study clearly demonstrates the best way to create a favourable microclimate by proper selection, amount, species and arrangement of landscaping for a tropical residential landscape.

\section{References}

Akbari, H., Davis, S., Dorsano, S., Huang, J., \& Winnet, S. (1992). Cooling our Communities, A Guidebook on Tree Planting and Light-Coloured Surfacing Washington: Lawrence Berkeley Laboratory.

Akbari, H., Taha, H., Huang, J., \& Rosenfeld, A. (1986). Undoing uncomfortable summer heat islands can save gigawatts of peak power. Paper presented at the The Panel on Small Building Technologies, Washington, DC.

DOE. (1993). Tomorrow's Energy Today for Cities and Countries: Cooling Our Cities U.S. Department of Energy, 16.

DOE. (1995). Landscaping for Energy Efficiency. Energy Efficiency and Renewable Energy, 10095 (046), 1-8.

Foster, R. S. (1994). Landscaping That Saves Energy and Dollars (Revised Ed.). USA: First Globe Pequot Edition.

McPherson, E. G., Herrington, L. P., \& Heisler, G. M. (1988). Impacts of vegetation on residential heating and cooling [Journal article ]. Energy and Buildings, 12, 41-51.

Morgan, R., McLeod, M., Mayfield, J., Richmond-Powers, M., Cohee, B., Gros, L., . . Nutt, L. (2000). Supplement to the Green Building Program. Austin, Texas Green Building Program.

Olgyay, V. (1963). Design with Climate Bioclimatic Approach to Architectural Regionalism New Jersey Princeton University Press.

PJH. (2001). Progress report for residential development at Sub-Precinct 14-9, Federal Territory Putrajaya, Putrajaya.

Simpson, J. R. (2002). Improved estimates of tree-shade effects on residential energy use. Energy and Buildings, 34 (10), 1067-1076. 
Misni, A. / Asian Journal of Behavioural Studies (AjBeS), 3(11) May / Jun 2018 (p.147-156)

Taiz, L., \& Zeiger, E. (2006). Plant Physiology (Fourth Edition Ed.). Massachusetts: Sinauer Associates, Inc. 